Asian Journal of Scientific Research 1 (1): 49-56, 2008

ISSN 1992-1454

(C) 2008 Asian Network for Scientific Information

\title{
Measurement of Oil Palm LAI by Manual and LAI-2000 Method
}

\author{
${ }^{1}$ M.A. Awal and ${ }^{2}$ W.I. Wan Ishak \\ ${ }^{1}$ Department of FPM, Bangladesh Agricultural University, Bangladesh \\ ${ }^{2}$ Department of Biological and Agriculture Engineering, UPM, Malaysia
}

\begin{abstract}
In this study, accurate Leaf Area Index (LAI) of different palm age groups were determined by manual (direct) method. Optical methods for quantifying variation in LAI of different palm ages were evaluated using LAI-2000 Plant Canopy Analyser (PCA) as an indirect method. In the manual method, LAI values obtained were $0.69,1.11,2.38,2.49$, $3.41,3.83,4.05$ and in the indirect method LAI values obtained were $1.75,1.4,1.14,1.42$, $2.87,1.89,3.05$ for $2,3,6,7,9,12$ and 16 year old palms, respectively. Results showed that the PCA LAI values were overestimated for immature palms but underestimated for mature palms. The PCA LAI values were overestimated by $30.8-153 \%$ for 2 to 3 -year old palms and underestimated by $24-52 \%$ for beyond 6 -year old palms as compared to manual measurement. The relationship between palm age and LAI was also established in this study. A strong linear relationship between direct LAI and palm age was observed with a correlation coefficient, $\mathrm{R}=0.90$. However, the relationship between PCA LAI and palm age was weak and not significant. A relationship was observed between PCA LAI and direct LAI with a correlation coefficient of $\mathrm{R}=0.57$. The study shows that it was possible to rapidly determine LAI using the LAI-2000 Plant Canopy Analyser. This rapid and non-destructive method saves labour when compared to manual measurements. However, this instrument gave inconsistent of LAI values in respect to oil palm age.
\end{abstract}

Key words: Leaf area index, measurement, plant canopy analyser, manual method, oil palm

\section{INTRODUCTION}

Leaf Area Index (LAI) is one of the most important parameters measured in oil palm physiological studies. It is needed in ecosystem analysis because of the importance of canopy structure in gas, water and carbon and energy exchange. LAI is frequently used for estimating evapotranspiration, net primary productivity and also crop growth model as an important input variable (Sellers et al., 1986). The estimation of LAI and description of the architecture of canopies has been the subject of considerable scientific research involving both experimental and modelling studies (Gardingen et al., 1999). Many direct and indirect methods have been used for measuring the leaf area index. In oil palm, direct methods are time consuming, difficult, laborious and costly. Direct measurement of LAI is only practicable on experimental plots of limited size. Consequently, estimating LAI over large areas is problematic (Gobron et al., 1997).

The plant canopy analyser (PCA) LAI-2000, which is used as an indirect method and LAI obtains on gap fraction at five view angles, is designed to work under diffuse light conditions (Leblan and Chen, 2001). The LAI-2000 has been widely used over a range of plant canopies: coniferous and deciduous species (Gower and Norman, 1991), different pines (Law et al., 2001) and boreal forest in Canada (Chen et al., 1997). Lamade and Setiyo (1996) evaluated the LAI-2000 on oil palms in Indonesia (i.e., 5 and 9 years after field planting) while Roslan et al. (2002) evaluated on 5 years old palm in Malaysia. Many of these studies showed that the LAI-2000 generally underestimates the LAI from direct measurements. However, indirect LAI measurements are sensitive to a range of external and internal 
Many of these studies showed that the LAI-2000 generally underestimates the LAI from direct measurements. However, indirect LAI measurements are sensitive to a range of external and internal factors such as foliage orientation, measuring time, spatial variation under canopy and weather condition, which often induce errors in the final LAI estimation (Awal et al., 2006). The objectives of this study were i) to determine the LAI of the oil palm by direct and LAI-2000 methods for different ages of the palm and ii) to compare direct and LAI-2000 methods for measuring LAI.

\section{MATERIALS AND METHODS}

\section{Study Site}

Measurements were made at the Malaysian Palm Oil Board (MPOB) research plot in 2004. MPOB is situated about $30 \mathrm{~km}$ north from Kuala-Lumpur, Latitude $2^{\circ} 58^{\prime} 0.36^{\prime \prime} \mathrm{N}$, Longitude $101^{\circ} 44^{\prime} 26^{\prime \prime} \mathrm{E}$ ) at an average altitude of $66.5 \mathrm{~m}$ from sea level. Commercial planting density of 148 palms per hectare and ages of $2,3,6,7,9,12$ and 16 years old palms were used for this investigation.

\section{LAI-2000 Plant Canopy Analyzer}

The LAI-2000 Plant Canopy Analyser (PCA) is an instrument designed to measure LAI of green canopies (Fig. 1). The instrument's sensor integrates with fisheye optics to project a hemispheric image onto five silicon detectors, arranged in concentric rings. The sensor also contains an optical filter to restrict sensed radiation of wavelengths below $490 \mathrm{~nm}$, in order to minimize the contribution of radiation that has been scattered by foliage (Welles and Norman, 1991).

This five sensors simultaneously measure the PAR light intensities in five concentric Field Of Views (FOVs) centred at zenith angles of $7,23,38,53$ and $68^{\circ}$, respectively referred to as PCA Sensors 1, 2, 3, 4 and 5. Usually, below- and above-canopy readings are simultaneously acquired to calculate the canopy gap fraction, which represents the probability of light penetration. Gap fraction values are then converted to contact frequency values that are used for further analysis (LI-COR, 1992). The LAI- 2000 potentially views a full $360^{\circ}$ of azimuth, which can be restricted by view cap of $270^{\circ}, 180^{\circ}, 90^{\circ}$ and $45^{\circ}$, attached onto the sensor head to limit sensor view for special purposes (Welles and Norman, 1991).

\section{Measurement of Leaf Area and LAI \\ Measurement of Leaf Area by Direct Method}

LAI derived from improved direct sampling methods was used for verification of LAI data sets obtained from indirect measurements. An experiment was conducted to determine the leaf area index in the field for $2,3,7,9,12$ and 16 years old palms. As a general rule, the leaf chosen is frond 17 , near the middle of the crown, which is assumed to be representative of the crown as a whole (Tailliez and Ballo Koffi, 1992). Therefore, Frond 17 was selected from each palm. A total of five fronds were selected and cut from each palm age groups. After cutting, the fronds were brought back the laboratory for analysis as soon as possible in order to prevent shrinkage. Leaflets from one-side of the frond were cut (Fig. 2) and the leaflet area measured using a potable leaf-area meter (LI-3000A, LICOR, USA) in order to determine true leaf area. The one-sided leaflet area was multiplied by two to obtain the total leaflet area of the frond. Leaf area index was then calculated using the Eq. 1.

According to the conventional method, we used the following equation to determine LAI:

$$
\mathrm{LAI}=\mathrm{A}_{\mathrm{f}} \times \mathrm{Fn} \times \mathrm{PDEN} / 10,000\left(\mathrm{~m}^{2} \mathrm{~m}^{-2}\right)
$$

Where:

$\mathrm{A}_{\mathrm{f}} \quad=$ The leaf area per frond $\left(\mathrm{m}^{2}\right)$.

Fn $=$ The number of frond per palm.

PDEN $=$ The planting density (number of palms per hectare). 


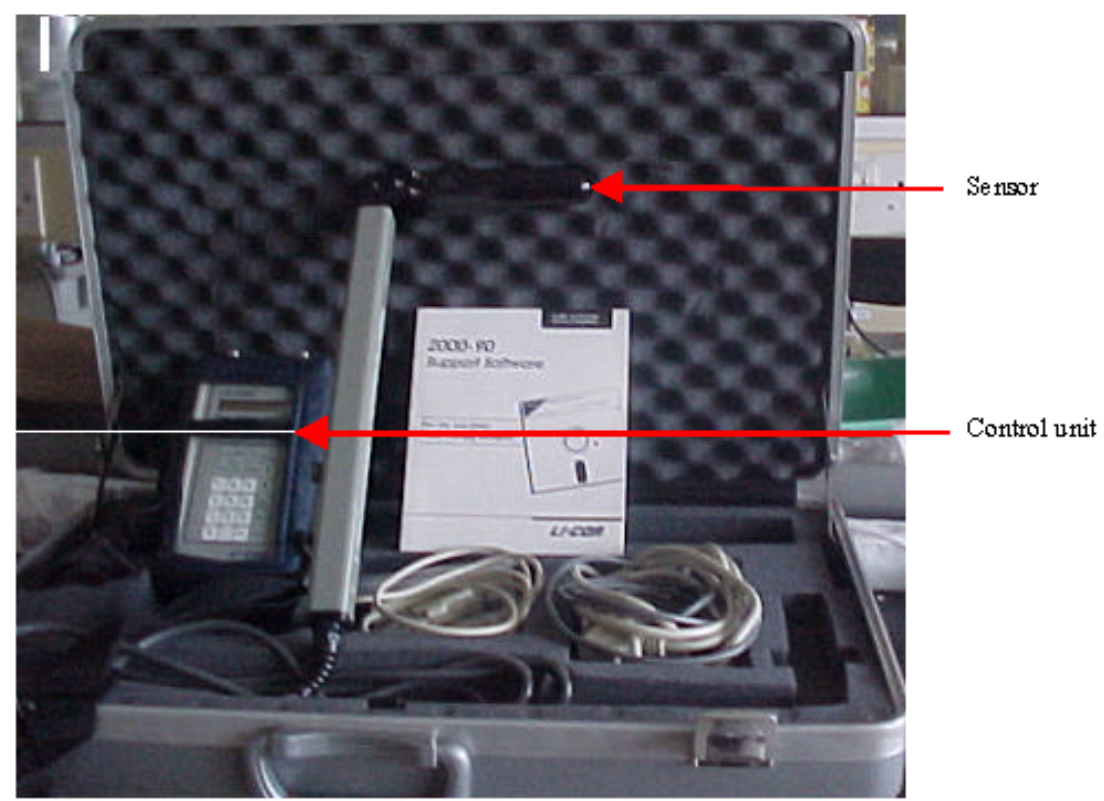

Fig. 1: LAI-2000 plant canopy analyser (LICOR, USA)

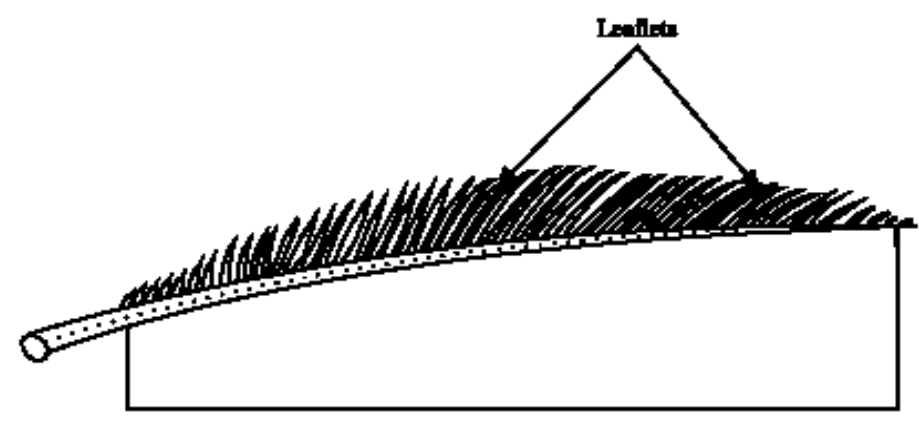

Fig. 2: Leaflet sampled from one side of frond 17

\section{LAI Determination Using P CA for Different Palm Age Groups}

Six different groups of palm ages (i.e., 2, 3, 7, 9, 12 and 16 year old) were selected for LAI detemination by PCA method in the field. Ten locations were selected for each palm age group. Four replications were used to determine the LAI in each age group. The sensor was placed just above the ground level ( $0 \mathrm{~m}$ height from ground) in immature palm ( 2 and 3 year old palms), whereas one-meter sensor height above the ground was used for mature $\mathrm{p}$ alm $(7,9,12$ and 16 year old palms). Zigzag method was used for LAI measurement of mature palm age groups (Fig. 3). Four equal measuring points between two adjacent palms were used for zigzag method. The one above and four below method was used for LAI measurement of immature palm age groups. In this method, one above reading and four bel ow reading were taken in North-South and East-West direction (Fig. 4). All PCA LAI-2000 readings were taken with the sensor-facing north at 1.4 meters above ground and with a 180-degree view cap attached. Measurements were taken early in the moming to minimize the direct effect of light on the LAI calculation. 


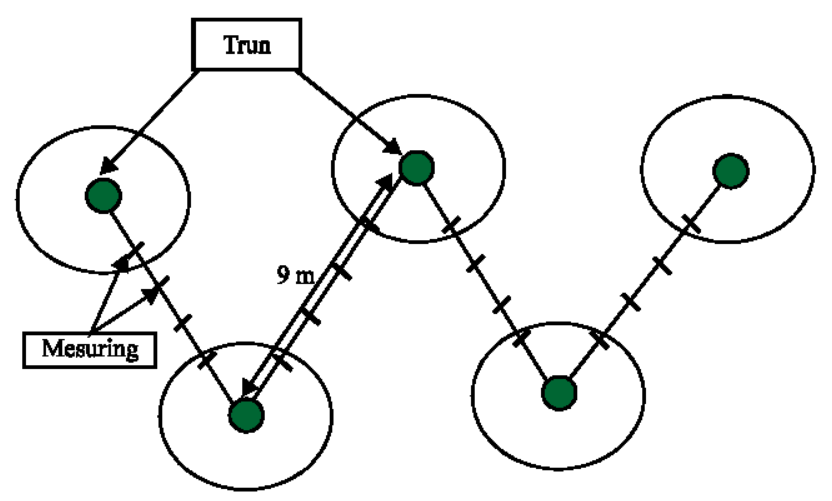

Fig. 3: Designs for taking below canopy reading measurements in mature oil palm

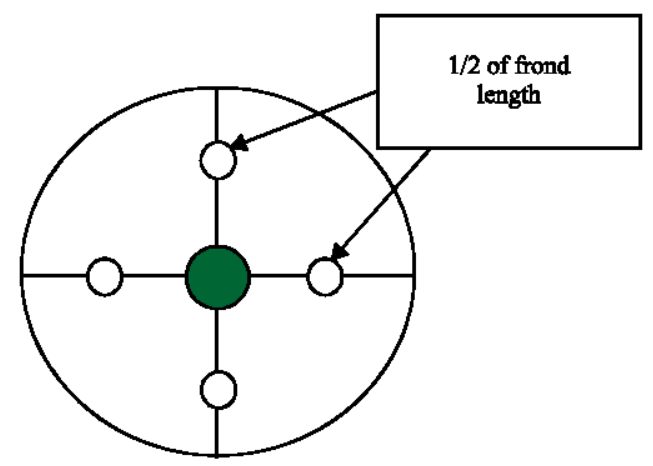

Fig. 4: Designs for taking below canopy reading measurements in immature oil palm

\section{RESULTS AND DISCUSSION}

\section{LAI Determination for Different Palm Age Groups}

\section{LAI Determination by Manual Method}

Table 1 shows the average LAI values were lowest for the 2 year old palms, while maximum LAI values were obtained in 16-year old palms. The ranges of the LAI values were 0.57 to 0.79 for the 2-year old palms and 3.12 to 5.02 were for the 16 year old palms, respectively.

Figure 5 shows the linear relationship between direct LAI and palm age. A strong relationship was found between palm age and direct LAI for linear regression analyses $(\mathrm{R}=0.90)$. Results indicate a high degree of association $\left(\mathrm{R}^{2}=0.82\right)$ between palm age and true LAI and the standard error of estimation was 0.45 . The standard error of estimate of coefficient was 0.037 and the standard error of estimate of constant was 0.01 for linear analyses.

\section{LAI Determination by LAI-2000 Method}

LAI for oil palm plantation varied with soil fertility, planting density, planting materials and agronomic inputs. However, LAI is expected to vary according to age of palm planting. In this study, PCA LAI was not found to have a linear relationship with palm age (Fig. 6). In immature palms, LAI values were high compared to the mature palm age groups. The range of LAI values in 2-year old palms were 1.591 to 1.922 , whereas for the 3 years old palm the range was 1.265 to 1.527 (Table 2). 
Table 1: Summary of average LAI values for 2 to 16 year old palms

\begin{tabular}{|c|c|c|c|}
\hline \multirow[b]{2}{*}{ Palm age (year) } & \multirow[b]{2}{*}{ Leaf Area Index (LAI) } & \multicolumn{2}{|c|}{$95 \%$ confidence interval } \\
\hline & & Lower & Upper \\
\hline 2 & $0.69 \pm 0.040$ & 0.570 & 0.795 \\
\hline 3 & $1.06 \pm 0.031$ & 0.977 & 1.154 \\
\hline 6 & $2.38 \pm 0.111$ & 2.076 & 2.694 \\
\hline 7 & $2.52 \pm 0.139$ & 2.137 & 2.914 \\
\hline 9 & $3.43 \pm 0.254$ & 2.730 & 4.145 \\
\hline 12 & $3.81 \pm 0.133$ & 3.441 & 4.184 \\
\hline 16 & $4.05 \pm 0.343$ & 3.121 & 5.027 \\
\hline
\end{tabular}

Table 2: Summary of PCA LAI values for 2 to 16 year old palms

\begin{tabular}{|c|c|c|c|}
\hline \multirow[b]{2}{*}{ Palm age (year) } & \multirow[b]{2}{*}{ Leaf Area Index (LAI) } & \multicolumn{2}{|c|}{$95 \%$ confidence interval } \\
\hline & & Lower & Upper \\
\hline 2 & $1.75 \pm 0.081$ & 1.591 & 1.922 \\
\hline 3 & $1.39 \pm 0.064$ & 1.265 & 1.527 \\
\hline 6 & $1.60 \pm 0.067$ & 1.468 & 1.743 \\
\hline 7 & $1.78 \pm 0.133$ & 1.512 & 2.051 \\
\hline 9 & $2.82 \pm 0.101$ & 2.615 & 3.025 \\
\hline 12 & $1.79 \pm 0.067$ & 1.660 & 1.934 \\
\hline 16 & $3.05 \pm 0.119$ & 2.798 & 3.281 \\
\hline
\end{tabular}

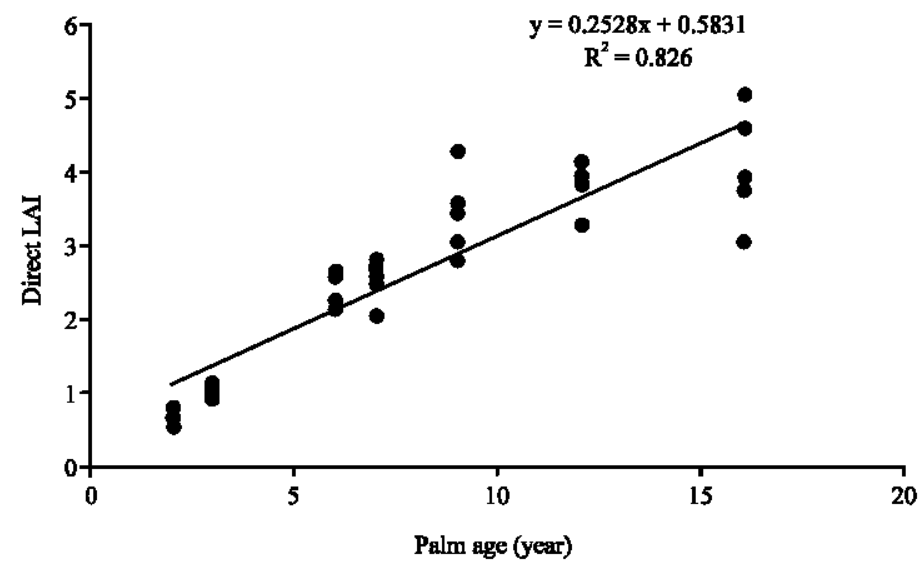

Fig. 5: Relationship between palm age and direct LAI

Maximum LAI values were observed in the 16 year old palms (2.798-3.281). Average LAI value of 9 years old palm was 2.82 , whereas for the 12 year old palms the average LAI value was 1.79 . This indicates that the LAI-2000 value does not depend on palm age.

Figure 6 shows the linear relationship between indirect LAI and palm age. Results show that the relationship between palm age and indirect $\mathrm{LAI}$ was weak and not significant $(\mathrm{R}=0.52)$. In oil palm plantations, LAI measurement by LAI-2000 method depends mainly on the density of foliage, arrangement of canopy and height and position of sensor.

\section{Comparison of LAI from Manual Method and LAI-2000 Method}

Table 3 shows the LAI values for the different palm age groups for the two methods. The measured LAI values using LAI-2000 was higher for immature palm and lower for mature palm compared to manual method. In the 2 year old palms, the indirect LAI value as overestimated by $153 \%$ as compared to the manual method. In the 3 year old palms, the indirect LAI value as also 


\begin{tabular}{llc} 
& LAI & \\
Palm age (year) & Direct method & Indirect (LAI-2000) method \\
\hline 2 & 0.69 & 1.75 \\
3 & 1.06 & 1.39 \\
6 & 2.38 & 1.60 \\
7 & 2.52 & 1.78 \\
9 & 3.43 & 2.82 \\
12 & 3.81 & 1.79 \\
16 & 4.05 & 3.05 \\
\hline
\end{tabular}

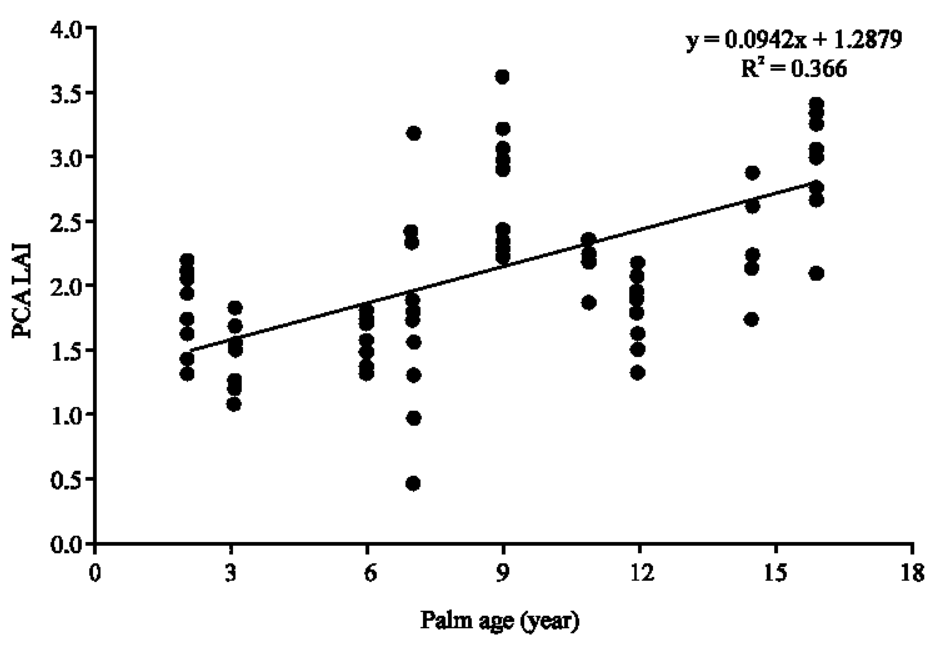

Fig. 6: PCA LAI value against palm age

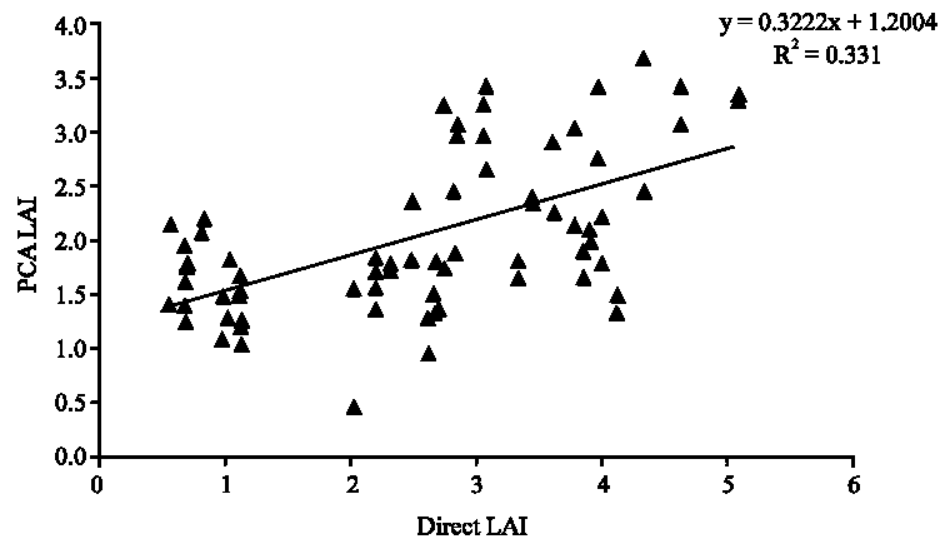

Fig. 7: Relationship between the direct and indirect LAI values

overestimated by about $30.8 \%$. For palm age above six year old, the indirect LAI values were underestimated at about (24-52\%) compared to the manual method. Lamade and Setiyo (1996) carried out an experiment on 10 year old palms using the LAI-2000 measurement technique and found that the LAI value was $40 \%$ less than the LAI obtained by direct measurement.

Figure 7 shows the relationship between the indirect and direct LAI values for 2 to 16 year old palms. A poor relationship observed with correlation coefficient, $\mathrm{R}=0.57$ between LAI-2000 method 


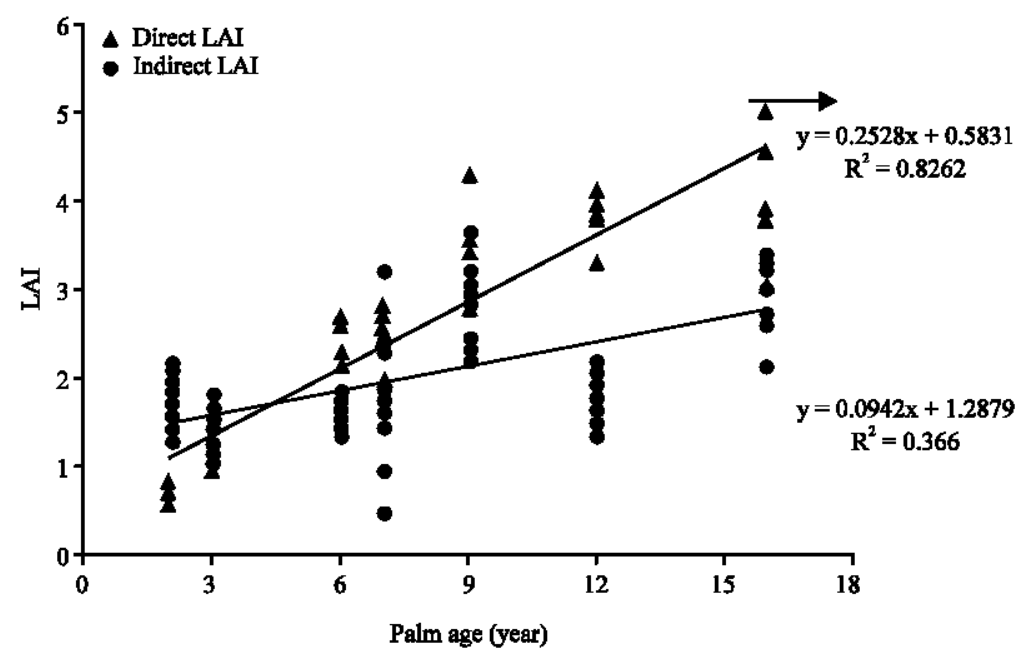

Fig. 8: Relationship between direct and indirect LAI with palm age

and direct method. Figure 8 shows the comparison LAI values for the different palm age groups for the two methods. Results show that in the 2 and 3 year old palms, the indirect LAI value was overestimated as compared to the direct method, while for the palm age above six year old, the indirect LAI values were underestimated as compared to the direct method.

Lamade and Setiyo (1996) carried out an experiment on 10 year old palms using the LAI-2000 measurement technique and found that the LAI value was $40 \%$ less than the LAI obtained by direct measurement. Villalobos et al. (1995) also carried out study on olive orchards (where leave contribute $91 \%$ to the total area) and took measurements of LAI by LAI-2000 PCA and found an underestimation of LAI of around $30 \%$. Chason et al. (1991) found an underestimation of the LAI of an oak-hickory forest by about $45 \%$, where a random spatial distribution of leaves was assumed. All of the above study showed that LAI-2000 generally underestimate LAI from direct measurement, which strongly supported present findings.

\section{CONCLUSIONS}

An obvious goal of using indirect techniques to estimate LAI was to compare with manual measurements, which are usually assumed to be more accurate and are typically the standard for comparison. However, manual methods are time consuming, laborious and destructive and often not permitted in oil palm plantation and also not suitable for tall palms. Compared to the manual methods, the LAI-2000 PCA is more rapid, non-destructive and can be used over wide areas and tall palms. The study shows that it was possible to rapidly determine LAI using the LAI-2000 Plant Canopy Analyzer. This rapid and non-destructive method saves labour when compared to manual measurements. The main disadvantage of the LAI-2000 PCA was inconsistency of LAI measurement. The indirect LAI values were underestimated by $45-50 \%$ for mature (above 6 year old) palms and overestimated by $153 \%$ for immature ( 2 to 3 year) Palms. In conclusion, LAI-000 PCA could be useful only for measuring relative variation in LAI rather than accurate LAI, where the main objective will be to monitor growth of the palm and LAI variation with season. 


\section{ACKNOWLEDGMENTS}

We appreciated the cooperation of Dr. Johari, Faculty of Engineering, UPM, Dr. Haniff, Senior Research Officer, MPOB and MPOB for helping us with valuable comments, logistic support as well as providing laboratory facilities and permission to harvest the fronds. The Author also acknowledge to Ministry of Science, Technology and Innovation for financial support to run this study.

\section{REFERENCES}

Awal, M.A., W. Ishak, J. Endan and M. Haniff, 2006. Measurement of leaf area index using optical methods (LAI-2000) in oil palm plantation: Accuracy and limitation assessment. Pertanika J. Trop. Agric. Malaysia, 29: (In Press).

Chason, J.W., D.D. Baldocchi and M.A. Huston, 1991. A comparison of direct and indirect methods for estimating forest canopy leaf area. Agric. For. Meteorol., 57: 107-128.

Chen, J.M., P.M. Rich, S.T. Gower, J.M. Norman and S. Plummer, 1997. Leaf area index of boreal forests: Theory, techniques and measurements. J. Geophys. Res., 102: 29429-29443.

Gardingen Van, P.R., G.E. Jackson, S. Hernandez-Daumas, G. Russell and L. Sharp, 1999. Leaf area index estimates obtained for clumped canopies using hemispherical photography. Agric. For. Meteorol., 94: 243-257.

Gobron, N., B. Pinty and M.M. Verstraete, 1997. Theoretical limits to the estimation of the leaf area index on the basis of visible and near-infrared remote sensing data. IEEE Trans. Geosci. Remote Sensing, 35: 1438-1445.

Gower, S.T. and J.M. Norman, 1991. Rapid estimation of leaf area index in conifer and broad-leaf plantations. Ecology, 72: 1896-1900.

Lamade, E. and I.E. Setiyo, 1996. A rapid method for estimating leaf area index with the Li-cor LAI 2000 PCA for oil palm. CIRAD-CP, BP 5035, 34032 Montpellier Cedex 1, France.

Law, B.E., A. Van Tuyl, A. Cescatti and D.D. Baldocchi, 2001. Estimation of leaf area index in opencanopy ponderosa pine forests at different success ional stages and management regimes in Oregon. Agric. For. Meteorol., 108: 1-14.

Leblan, G.S. and M.J. Chen, 2001. A practical scheme for correcting multiple scattering effects on optical LAI measurements. Agric. For. Meteorol., 110: 125-139.

Roslan, M.H.H., S.N.A. Mustakin, A. Badrishah and A. Maurad, 2002. Indirect methods for measuring oil palm Leaf Area Index (LAI). MPOB Information Series. MPOB TT No. 130.

Sellers, P.J., Y. Mintz, Y.C. Sud and A. Dalcher, 1986. A simple biosphere model (SiB) for use with general circulation models. J. Atmos. Sci., 43: 505-531.

Tailliez, B. and C. Ballo Koffi, 1992. A method for measuring oil pal leaf area. Oleagineux, 47: 537-545.

Villalobos, F.J., F. Orgaz and L. Mateos, 1995. Non-destructive measurement of leaf area in olive trees using a gap inversion methods. Agric. For. Meteorol., 73: 29-42.

Welles, J.M. and J.M. Norman, 1991. Instrument for indirect measurement of canopy architecture. Agron. J., 83: 818-825. 